\title{
Comunicação, redes sociais e desafios da interculturalidade na sociedade contemporânea: casos IAC e Adidas
}

Communication, social networks and challenges of the interculturality in the contemporary society: IAC and Adidas cases

Comunicación, redes sociales y los desafíos de la interculturalidad en la sociedad contemporánea: casos IAC y Adidas

\section{Marcelo da Silva}

- Doutorando em Comunicação Social pela Universidade Metodista de São Paulo (Umesp)

- Mestre em Comunicação pela Universidade Estadual Paulista (Unesp-Bauru)

- Graduado em Relações Públicas pela Unesp-Bauru

- Professor da Universidade Federal do Maranhão (UFMA)

- E-mail: marcelosilva_rp@hotmail.com

(9) Katarini Giroldo Miguel

- Doutora em Comunicação Social pela Universidade Metodista de São Paulo (Umesp)

- Mestre em Comunicação pela Unesp-Bauru, (Umesp)

- Graduada em Jornalismo pela Universidade do Sagrado Coração (USC), Bauru

- Professora adjunta de Jornalismo na Universidade Federal de Mato Grosso do Sul (UFMS)

- E-mail:k-miguel@uol.com.br

(9) Jéssica de Cássia Rossi

- Doutoranda em Ciências Sociais na Unesp-Marília

- Mestra em Comunicação pela Universidade Estadual Paulista (Unesp-Bauru)

- Graduada em Relações Públicas pela Unesp-Bauru

- Professora dos cursos de Relações Públicas, Jornalismo e Publicidade da Universidade Sagrado Coração (USC), Bauru

- E-mail: jessicacrossi@yahoo.com.br 


\section{Resumo}

Este artigo discute as proposições da comunicação intercultural para as organizações contemporâneas, em um contexto de sociedade largamente globalizado, que recombina informação e comunicação nas plataformas digitais, manifestando suas alteridades e diferenças culturais. Analisamos exploratória e descritivamente dois casos que ilustram essas concepções: o de uma funcionária da empresa IAC, após emitir comentário racista em rede social, e o da Adidas, que teve que retirar produtos de circulação após manifestos e acusações de apelo sexual de consumidores brasileiros.

\section{PALAVRAS CHAVE: COMUNICAÇÃO • COMUNICAÇÃO ORGANIZACIONAL・INTERCULTURALIDADE • REDES SOCIAIS.}

\section{Abstract}

The article discusses the proposals of intercultural communication for contemporary organizations, in a context of a largely globalized society, which recombine information and communication on the digital platforms, showing their otherness and cultural differences. We have analyzed on an exploratory and descriptive basis two cases that show these concepts: that of an employee of the IAC corporation, after making a racist comment on a social network, and of Adidas, which had to remove products from the market, after manifestations and accusations of sex appeal of the Brazilian consumers.

\section{KEYWORDS: COMMUNICATION・ORGANIZATIONAL COMMUNICATION・INTERCULTURALITY・SOCIAL NETWORKS.}

\section{Resumen}

El artículo discute las proposiciones de la comunicación intercultural para las organizaciones contemporáneas, en un contexto de sociedad ampliamente globalizada, que recombina la información y la comunicación en las plataformas digitales, mostrando sus alteridades y diferencias culturales. Analizamos de manera exploratoria y descriptiva dos casos que ilustran estos conceptos: el de una empleada de la empresa IAC, tras emitir un comentario racista en red social, y el de la Adidas, que tuvo que retirar productos de circulación, después de manifestaciones y acusaciones de apelo sexual por parte de los consumidores brasileros. 
ivemos em uma sociedade carregada de informações, perpassada de realidades espetacularizadas por uma enorme quantidade de imagens que nos rodeiam e nos afetam em todos os níveis: consciente, imaginário, inconsciente, social, individual, emocional e racional; o contexto no qual estamos inseridos traz à tona uma configuração que cria relações de resistência e de integração ao universo construído pelo desenvolvimento urbano e pela legitimação dos meios de comunicação e das tecnologias digitais.

A sociedade tem se tecido - e sido tecida - na possibilidade de que a tecnologia e todo o seu aporte potencializem as destrezas e capacidades humanas; entretanto, em que pesem suas contribuições ao homem, eles, ao mesmo tempo, ativam uma lógica de dependência recortada pelo individualismo exacerbado, que, conforme Gilles Lipovetsky (2004) se caracteriza por: 1. Ações investidas de egoísmo nas quais o sujeito se sente o centro do universo e investe tempo na realização de desejos e necessidades, independentemente dos meios; 2 . Relações sociais reduzidas à competição, não interessando a alteridade e seus sentimentos; 3. Consumo que gera pertencimento, poder e diferenciação social; 4. Intolerância concretizada em ideias e atitudes que desconsideram o outro e a diversidade cultural, étnica, religiosa e comportamental.

Nessas caracterizações vemos imerso o mundo da informação e da comunicação organizacional, de maneira que a estruturação de programas e planos de comunicação voltados para os diferentes públicos duelam com essa realidade cada vez incontrolável. Haja vista a complexidade do sujeito que atua no interior das organizações, sujeito este pertencente a diferentes mediações e que costura a cotidianidade por meio de representações que nem semprecedem aos imperativos sociais, midiáticos ou organizacionais.

Nesse sentido, apresentamos um estudo exploratório de dois casos emblemáticos que refletem o contexto das organizações contemporâneas e a forma como lidam com a comunicação intercultural. No primeiro deles, uma funcionária da IAC organização que gerencia redes sociais digitais - expressou no Twitter um comentário claramente preconceituoso sobre a África do Sul, o qual repercutiu a ponto da organização responder publicamente' . Já no segundo, a empresa Adidas teve que retirar de circulação sua linha de camisetas referentes à Copa do Mundo, com representação estereotipada da mulher brasileira por meio de apelo sexual, que suscitou diferentes manifestações contrárias à marca² .

Esses casos ligam-seao universo dacomunicação e da informação eà forma como a sociabilidade tem se produzido nas interações sociais em diferentes ambiências. Todavia, antes de adentrarmos nas análises, é necessário discutir mais amplamente as diferenças entre comunicação e informação e conceituar a comunicação intercultural que colocamos em foco.

Comunicação e informação não podem ser confundidas. A informação pode ser compreendida em termos de psicologia cognitiva, modelos matemáticos, sistema massa-energia e no interior de uma teoria da forma. A questão fundamental que caracteriza uma e outra é a recepção, ou seja, a alteridade, o elemento-chave no esquema comunicativo proposto por diferentes abordagens dos estudos da comunicação.

Em uma sociedade pluriconectada, precisamos conviver com as diferenças e lançar olhares à necessidade da convivência em uma aldeia global que é uma cacofonia da torre de babel; a comunicação foi, durante muito tempo, impossibilitada pela ausência de técnicas apropriadas que se ajustassem às demandas sociais. "Ontem a dificuldade para abordar o outro ilustrava

O comentário de Justine Sacco em seu perfil no Twitter pode ser acessado por meio do endereço http://www.twitter.com/JustineeSacco. 
a dificuldade de comunicar com ele", ao passo que atualmente, "a facilidade de comunicar dá o falso sentimento de que seria mais fácil compreender-se" (Wolton, 2006, p.19). Dessa maneira, o movimento globalizador do mundo, no lugar de produzir compreensão, acirra as diferenças, os embates e as contradições, como observamos nos casos da Adidas e da empresa IAC, os quais evidenciam que o trabalho de comunicação transcende a mera técnica e nos interpela quanto ao conhecimento e ao cuidado com nossas percepções do outro nos contextos locais, regionais, globais e interculturais.

A comunicação, em seu sentido mais amplo, deveria - por meio do aporte tecnológico - fomentar aproximações de pontos de vista, produzindo mais respeito; ao contrário, vemos o alargamento das visibilidades e a incompreensão do mundo e do outro. 0 par cultura-comunicação e as técnicas da informação emergem nas problemáticas políticas da globalização e, no lugar de promover novas condições que permitam "a ampliação do conhecimento do planeta, dos objetos que o formam, das sociedades que o habitam e dos homens" (Santos, 2013, p. 38), são megafones utilizados por alguns poucos atores sociais em função de objetivos e estratégias privados. Segundo Santos (2013, p. 39), determinadas técnicas são apropriadas por alguns estados e empresas, "aprofundando os processos de criação de desigualdades" e de incomunicação.

A dupla dimensão da comunicação - a normativa e a funcional - deveria entrelaçar-se, equilibrando o lado humano e o técnico, já que as relações humanas podem ser estritamente funcionais, permitindo trocas bastante autênticas, e apontar para uma condição: 0 olhar para a alteridade. Wolton (2006, p. 16) afirma que, independentemente do suporte, a informação permanece no nível da mensagem, da produção e distribuição o mais livremente possível, ao passo que a comunicação não se resume a processos de transmissão. Haja vista que ela enseja um processo de apropriação que considere as condições em que o receptor "recebe, aceita, recusa, remodela" as mensagens, em razão de seu horizonte filosófico, político, cultural, social e idiossincrático.

A história da emancipação do homem imbrica-se na informação e na comunicação ${ }^{3}$, porque, por meio da liberdade de expressão, o espírito crítico e o conhecimento do mundo foram se erigindo; se nos séculos XIX e XX o nó górdio era a construção dessa liberdade de informação e expressão com o apoio do progresso tecnológico, no século XXI, um dos desafios habita "a organização da convivência pacífica entre os pontos de vista contraditórios num mundo onde cada um vê tudo e quer conservar sua identidade e sua liberdade de expressão" (Wolton, 2011, p. 87).

A dinâmica se complexifica no interior da comunicação eletrônica, em rede, aquela pautada pelas mídias sociais digitais, que confunde informação e comunicação em um ambiente de constante transformação e papeis indefinidos.

\section{CONSIDERAÇÕES SOBRE REDES SOCIAIS DIGITAIS}

Nos meios de comunicação eletrônicos há considerável volatilidade das informações, que são facilmente reprodutíveis com a digitalização e fragilizadas com a velocidade de circulação e disseminação; o potencial da tecnologia pode nos iludir, confundindo informação, comunicação e conhecimento. Esse cenário carrega suas antinomias abafadas pela retórica da "tecnologia transformadora e revolucionária" do homem e do mundo.

3 Pensamos que foi graças à comunicação que a igualdade entre as pessoas e a legitimidade do diálogo ganharam terreno na vida social, tanto nos meios de comunicação de massa como nas organizações. 
Essas questões desenham um espectro da comunicação como essência do ser, ou seja, a busca da autonomia e da identidade, haja vista que se torna basilar o reconhecer da importância da alteridade, ir ao seu encontro, aceitar certa dependência dela e a incerteza de que haverá intercompreensão. Isso nos leva à ruptura do conhecimento ligado ao prêt-à-penser da comunicação como manipulação e persuasão, bem como da panaceia que seriam as redes e mídias sociais digitais.

As redes sociais digitais propiciam, obviamente, um movimento interessante à medida que permitem ao usuário se visibilizar, se manifestar, produzir e compartilhar informações de seu espectro de interesse, bem como superar as lógicas tradicionais de consumo de informação, além de, ainda, atuar politicamente, barrar comportamentos abusivos e exigir postura ética de diferentes organizações. Contudo, é iminente que a liberação total da palavra, a profusão de dados e o leviano engajamento gerem conflitos de informação e de natureza cultural. Essas questões são tratadas por Ramonet (2013), que vislumbra 0 esgotamento dos monopólios midiáticos com a emergência dos meios 'polvos', que com seus vários tentáculos permitem ao cidadão 'comum' produzir-emitir-receber informações de diferentes níveis.

Participamos, de fato, de um contexto contemporâneo de "comunicação" ubíqua, facilitado pelas tecnologias, e é preciso entender o funcionamento das redes sociais digitais, que se transvestem em plataformas de comunicação cotidiana, de expressão, de ação política, ainda que desorganizada. Situamos redes sociais digitais como conjunto de atores e suas conexões, um sistema de comunicação pela Internet (daí explicitar o termo digital) que conecta redes de pessoas, um espaço de autonomia que foge do controle de governos e empresas (Castells, 2013; Recuero, 2010).

As redes são dinâmicas, envolvem diferentes formações e interesses, extrapolam em amplitude a vivência presencial, transcendem barreiras geográficas e culturais e aumentam o potencial da informação. Permitem construir um perfil público e articular-se com uma lista de usuário, criar, fortalecer vínculos, estabelecer inúmeras conexões por meio do aparato técnico.

Entre as características das redes sociais digitais, elencadas por Recuero (2009), estão a persistência da informação, sua alta capacidade de replicabilidade (com alcance, muitas vezes imensurável) e a emergência de audiências invisíveis e incontroláveis.

As informações que circulam nas redes sociais assim tornam-se persistentes, capazes de ser buscadas e organizadas, direcionadas a audiências invisíveis e facilmente replicáveis. A essas características soma-se o fato de que a circulação de informações é também uma circulação de valor social, que gera impactos na rede (Recuero, 2009, p. 5).

As redes sociais digitais atuam, como lembra Recuero (2009), na produção (criação propriamente dita), na seleção e na reverberação de informação, ou seja, dão alcance aos fatos, difundem e provocam o debate, são capazes de subverter 0 mainstream da grande mídia, com contrafluxo de informação. A mobilização surge, não de maneira organizada, mas espontânea, na marcha cotidiana dos diversos assuntos que permeiam as redes.

As informações circulam com base justamente em valor agregado, em capital social, naquilo que o autor quer repassar. São motivações individualizadas, difíceis de prever, mas implicam a construção de identidades (múltiplas), a partir de uma causa, uma opção política. A identidade individual própria da internet se funde no coletivo das redes e acarreta consensos e dissensos. Nos casos aqui analisados - Adidas e IAC - verificamos a capacidade de replicação das mensagens e 0 alcance que adquirirem, gerando repercussão que inundou o ciberespaço e fora dele, e obrigou grandes organizações a darem explicações em público (e até a mudarem suas estratégias de produção). 
Temos dois episódios ilustrativos com as organizações que se desculparam publicamente por condutas preconceituosas, devido à repercussão das redes, e que podem ser balizados nessa concepção: as redes conseguem colocar valores em xeque, mas são um espelho da sociedade fragilizada e em constante mutação. Os comportamentos e as declarações das empresas apontam certa dificuldade em compreender o outro, como a comunicação intercultural nos propõe. No próximo item aprofundamos nossas reflexões sobre o tema.

\section{COMUNICAÇÃO INTERCULTURAL: OLHARES}

0 contexto de globalização e as novas tecnologias proporcionam uma aproximação cada vez maior de culturas diversas. Dessa forma, vivemos um período de intensas trocas culturais. Tal situação tem nos levado a pensar como ocorrem essas interações e quais os desafios que elas nos impõem. É neste âmbito que encontramos o conceito de interculturalidade, um termo que expressa uma variedade de referências nas quais estamos imersos e que denominam uma intensa relação entre culturas híbridas, resultado de experiências e tradições culturais ocorridas ao longo da história.

0 conceito de interculturalidade admite certos sentidos que são específicos dele, haja vista que tipifica a dinâmica que se dá entre as comunidades e as relações que ocorrem entre elas. Entretanto, não podemos pensar essas interações como um contato entre culturas que se mesclam e se integram. Na realidade, seria a possibilidade de participação de várias culturas, mas com identificação diferenciada, uma construção em comum que reconhece as diferenças culturais e busca a cooperação e o respeito (Rodrigo Alsina, 1990).

Uma maneira pertinente de refletirmos acerca do conceito de "intercultural" é a partir da preocupação da comunicação entre indivíduos portadores de diferentes culturas. A barreira para uma comunicação intercultural é o desconhecimento das outras culturas, fato que, na possibilidade de um contato, pode nos levar a perceber a dimensão da nossa ignorância em relação às alteridades. A melhor forma de nos relacionarmos, neste caso, não é sobredimensionando as diferenças culturais, senão as comparando, haja vista que, à medida que constatamos as igualdades, as diferenças e as similaridades, construímos 0 outro como distinto. Destarte, alguns dos principais óbices da comunicação intercultural são a generalização, a ignorância, a dimensão das diferenças e a universalização a partir de si.

Na cultura contemporânea, o diálogo tem desaparecido, não há mais disposição para se discutir as ideias do "adversário", pois antes mesmo de sabermos do que se trata, desqualificamos aquilo que os outros pensam. O leque de cosmovisões humanas é ignorado e sua riqueza diminuída quando não aceitamos o diferente. Usamos apenas juízos de valor cristalizados em todas as formas de estereótipos e preconceitos, diminuindo a grandeza da vida humana frente ao fracasso do projeto existencial da humanidade. Nesse contexto, é importante atentarmos para as formas de relacionamento que desenvolvemos nas redes sociais digitais.

A construção de uma competência intercultural passa pela capacidade de negociação de significados culturais e pela ação comunicativa eficaz, de acordo com as múltiplas identidades dos participantes. Contudo, essa eficácia não ocorre por meio de um diálogo perfeito, controlado e sem ambiguidades; ao contrário, dada sua dificuldade mesmo para interlocutores de uma mesma cultura. Cada pessoa possui um conjunto de conhecimentos diferenciados que conduz as suas interpretações acerca da realidade, sendo que toda mensagem pode ser mais compreendida ou menos, dependendo da proximidade de conhecimentos e de cognição de cada indivíduo. 
Apesar de todas as dificuldades, o diálogo intercultural é relevante na hodiernidade por envolver uma intensa troca de experiências em que tudo está sujeito a críticas e a mudanças. A interculturalidade acontece justo no momento em que começamos a entender o sentido que as coisas têm para a alteridade. Ela se aprofunda à medida que conhecemos os significados do outro, conforme o modo de ser de cada um é compartilhado nas práticas sociais (e atualmente nas redes sociais digitais) que constroem formas de sociabilidade que se atualizam nas diferentes idiossincrasias e contextos.

No mundo corporativo, a gestão dos relacionamentos interculturais também é importante, já que o capitalismo global tem intensificado a interação entre as organizações e os grupos sociais de diferentes culturas. Por isso, o comportamento intercultural éum desafio que deve ser incorporado pela comunicação organizacional. As relações com públicos de outros países não são efêmeras, elas devem ser sólidas, a fim de que a identidade e a imagem das organizações não sejam comprometidas (Ferrari, 2013). É necessário entender profundamente o contexto intercultural, já que as ações e os discursos em ambientes interculturais devem ser guiados por um conhecimento profundo dos significados de cada grupo (Ribeiro, 2003).

Tendo isso em vista, nossas análises verificam como foi a gestão do relacionamento intercultural de organizações com seus stakeholders em duas situações específicas. A primeira refere-se ao discurso racista da ex-diretora de comunicação, Justine Sacco, da empresa IAC em uma rede social, e o segundo caso, sobre o lançamento de uma linha de produtos da Adidas sobre o Brasil e a Copa do Mundo de 2014, que foi rejeitada pelos brasileiros. As duas ocorrências ganharam as redes sociais digitais, em especial o Twitter e o Facebook, durante os meses de dezembro de 2013 e fevereiro de 2014, com repercussão significativa. Nosso estudo se baseou nos postsconstantes nessas redes eque podem ser acessados por meio de notícias digitais ${ }^{4}$. Para tanto, fizemos uso de descrições e interpretação dos discursos, na tentativa de entender essas construções de forma exploratória.

\section{COMENTÁRIOS PRECONCEITUOSOS NO TWITTER: E A ALTERIDADE?}

A gestão das relações interculturais é um desafio premente para a comunicação organizacional em diferentes situações de interação entre as organizações e grupos sociais diversos, ainda mais na sociedade de informação contemporânea, em que se potencializam os relacionamentos funcionais da comunicação (Wolton, 2006), intensificando os conflitos interculturais. Nesse sentido, o discurso é um recurso que pode expressar a competência intercultural das empresas com seus públicos de interesse.

0 primeiro caso refere-se à empresa norte-americana InterActiveCorp (IAC), que gerencia redes sociais digitais como Vimeo, Tinder, CollegeHumor, Dictionary.com e BlackPeopleMeet.com (portal de relacionamento voltado para negros). No dia 21 de dezembro de 2013, a então diretora de comunicação da organização, Justine Sacco, postou um comentário em seu perfil social no Twitter antes de viajar para a África. A profissional de relações públicas escreveu o seguinte: "Indo para a África. Espero que não pegue aids. Brincadeira. Eu sou branca".

Esse comentário - uma forma de discurso eivada de ideologia - engendra um tom preconceituoso e racista sobre os africanos. Embora tenha sido um comentário a respeito de uma situação particular da profissional, isso pode influenciar na imagem da IAC, haja vista que Justine representa a empresa e as pessoas podem entender que os valores da profissional de relações públicas sejam também os valores da organização, em uma relação de silogismo.

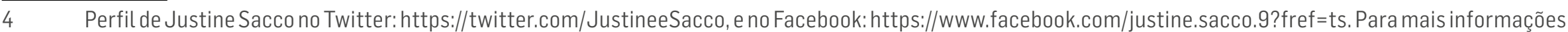

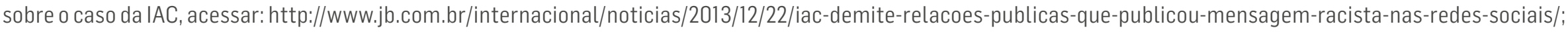
para o caso da Adidas: http://exame.abril.com.br/marketing/noticias/adidas-retira-das-lojas-camisetas-com-apelo-sexual. 
Após a publicação da mensagem no Twiter, o comentário foi replicado 619 vezes, curtido 380 vezes 5 e provocou uma repercussão negativa enquanto Justine viajava para a África do Sul. Nesse ponto, com base nas reflexões de Recuero (2009), verificamos a força das redes sociais digitais ao reproduzir o comentário de Justine de forma incontrolável, provocando diversas reações nos usuários das redes, os quais interpretaram a mensagem de forma bastante hostil, por entenderem a atitude da comunicadora como desrespeitosa em relação ao outro, ou seja, sem considerar a relevância da interculturalidade para a compreensão e a convivência com as diversas alteridades do mundo off-linee on-line. Diante dessa situação, a IAC afirmou que:

É um comentário ultrajante, ofensivo que não reflete a visão e os valores da IAC. Infelizmente, a funcionária em questão está fora de contato, num voo internacional, mas essa é uma questão muito séria e nós estamos tomando as providências necessárias (IAC, apud Nogueira, 2013, p. 1).

Por essa mensagem, a organização mostrou seu posicionamento acerca da situação, a fim de evitar conflitos com os seus stakeholders, ainda mais porque é responsável por um portal de relacionamento voltado especificamente para negros. Seria muito incoerente promover um serviço para negros e compactuar com comentários racistas. Para se construir uma reputação coerente, a ação e o discurso devem ser compatíveis.

As informações que circulam nas redes sociais digitais, além de transfronteiriças influenciam na construção da reputação das pessoas e organizações perante certos grupos. No caso da executiva, o comentário em questão causou uma reputação negativa para ela e, por extensão, para a IAC.

Após o ocorrido, a profissional de comunicação postou o seguinte comentário no Facebook ${ }^{6}$ : "Fiz uma enorme estupidez, eu profundamente peço desculpas. Longe de mim a ideia racista, era apenas para risos". Até o dia 23 de julho de 2014, o post teve 207 compartilhamentos e uma curtida. Contudo, isso não foi suficiente para resolver a situação, pois seus comentários demonstraram sua dificuldade em compreender o outro, ou seja, em viver situações de reconhecimento de diferenças, de aceitação da alteridade. Essa competência um profissional de comunicação - e de outras áreas também - deve ter, quando atua na perspectiva intercultural, porque precisa escutar o que o outro tem a dizer para promover o equilíbrio de interesses entre uma organização e "esse outro".

No dia 21 de dezembro de 2013, a IAC demitiu sua diretora de comunicação e publicou a seguinte nota:

A funcionária em questão foi desligada. Não há desculpa para aquelas demonstrações de ódio, e nós a condenamos. Esperamos, no entanto, que o tempo e o espírito humano possam perdoá-la, e que tudo isso não resulte em uma condenação de uma pessoa que, em outras circunstâncias, foi decente no fundo (IAC, apud Jornal do Brasil, 2013, p. 1).

A organização demonstrou seu repúdio em relação à situação, ao demitir Justine para evitar que sua reputação se negativasse frente a seus públicos de interesse e ao público em geral que teve acesso ao conteúdo enunciado pela profissional de relações públicas, a qual preferiu não se pronunciar sobre o ocorrido, mesmo após a insistência de muitos jornalistas.

Embora a IAC tenha sido coerente em sua ação e seu discurso, há relatos de que Justine já teria postado outros comentários preconceituosos anteriormente, principalmente sobre grupos marginalizados/indefesos como: "Eu tive um sonho erótico com

5 Essas informações foram extraídas no dia 23 de julho de 2014 do perfil de Justine Sacco no Twitter: https://twitter.com/JustineeSacco.

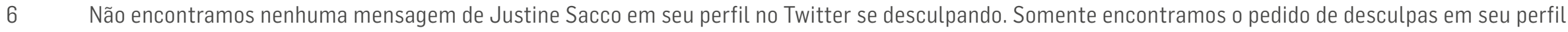
no Facebook. 
um garoto autista na noite passada". Por isso, questionamos por que a empresa não atentou para esses comentários antes, já que Justine foi uma executiva importante do grupo, o que exigia dela uma postura de respeito pelo outro.

Além disso, a própria Justine, por ser uma profissional de relações públicas, deveria ter respeito e compreensão pelo outro, competência básica para qualquer gestor de comunicação - e, digamos de passagem, de qualquer ser humano. Conforme verificamosanteriormente, no contextoglobale tecnológico contemporâneo, háo aumento das visibilidadese da incompreensão do mundo e do outro. A alteridade e a dimensão normativa da comunicação são comportamentos que têm sido obnubilados pela dimensão funcional da comunicação organizacional.

\section{ADIDAS, CULTURA E O "ALTER-BRASIL" ESTEREOTIPADO}

O segundo caso refere-se à Adidas, uma marca de origem alemã de equipamentos desportivos, atualmente considerada a maior empresa do ramo no mundo e presente em diversos países (Sua Franquia, 2014, p. 1). A marca foi a patrocinadora oficial da Copa do Mundo de 2014, promovida pela Fifa no Brasil. Assim, em fevereiro de 2014, a empresa lançou duas camisetas sobre o país. A primeira trazia o desenho de uma mulata ao lado da paisagem do Pão de Açúcar, no Rio de Janeiro, com uma expressão ambígua "Lookin' to score", a qual pode ser traduzida como "buscando gols" ou "querendo faturar", em sentido sexual, e a segunda camiseta tinha uma figura de um coração na forma de um corpo feminino usando um "fio dental", com a expressão "I love Brasil".

Os produtos não foram bem recebidos pelo governo brasileiro, para o qual as figuras denotam apelo sexual. 0 Instituto Brasileiro de Turismo (Embratur) receou de que os produtos estimulariam o turismo sexual durante a Copa do Mundo. 0 turismo sexual é um fenômeno que vem sendo combatido pelo governo brasileiro após um longo período de exibição de propaganda para incentivar o turismo no Brasil nos anos 1970 e 1980, que sensualizaram o país ao redor do mundo. Dessa forma, a Embratur vem adotando uma linha de comunicação que não admite o incentivo ao turismo sexual no país. Por isso, após o ocorrido, essa informação foi reforçada pelo instituto às suas agências ao redor do mundo (Dino, 2014, p.1).

O caso gerou repercussão e foi pauta nas redes sociais, inclusive, por parte de autoridades brasileiras, como a presidente Dilma Rousseff, que postou quatro comentários no Twitter, sem citar diretamente a empresa, mas enfatizando que o país está pronto para combater o turismo sexual ${ }^{7}$. Ao mesmo tempo, os consumidores reclamaram e se mobilizaram virtualmente, exigindo resposta da Adidas pela conduta apelativa (Agência Brasil, 2014, p. 1). 0 caso ganhou repercussão espontânea e confirma a capacidade das redes sociais digitais de reverberarem temas, ultrapassando a mídia convencional e exigindo resposta imediata de grandes empresas (Recuero, 2009).

Diante disso, a empresa retirou a linha de produtos do mercado, em respeito aos seus consumidores e parceiros, dizendo que

a Adidas sempre acompanha de perto a opinião de seus consumidores e parceiros e, por isso, anuncia que os produtos em questão não serão comercializado pela marca. É importante frisar que trata-se de uma edição limitada que estaria disponível apenas para os Estados Unidos (Adidas, apud Coutinho, 2014, p.1). 
Afirmar que o produto seria uma "edição limitada" para o público norte-americano não resolve o problema, mas reforça estereótipos sobre o Brasil, os quais ocultam o que a nação realmente é. A empresa agiu corretamente ao retirar os produtos e respeitar os relacionamentos interculturais e a repulsa dos consumidores. Há claramente um objetivo mercadológico que reflete a necessidade da empresa de conhecer e identificar os interesses de seus públicos por meio de diagnósticos, como prega a comunicação organizacional intercultural. Uma organização deve considerar os limites linguísticos e culturais e compreender que todo produto carrega em si uma dimensão do outro que o consumirá. Ao se realizar tal ação, a Adidas poderia ter verificado que as figuras e legendas em questão são vistas de forma negativa pelo público brasileiro; concomitantemente a isso, deveria ter tido ideia do efeito que seus discursos poderiam produzir no Brasil.

Isso traz à tona que o setor de comunicação da Adidas não praticou a comunicação organizacional a partir dos princípios da interculturalidade, os quais promovem interações democráticas entre a organização e seus stakeholders, considerando os múltiplos e complexos contextos sociais e culturais. Consideremos, na esteira de Wolton (2006, p. 107), que "a globalização das empresas traz à luz agora competências indispensáveis em termos de gestão multicultural e desenvolvimento".

Nesse espectro, é fulcral que se escute o que o outro tem a dizer, se compreenda e respeite os seus valores, ou seja, 0 gerenciamento da comunicação intercultural por meio da comunicação corporativa exige expertise humana, poder de negociação e empatia. São comportamentos muito raros na sociedade de informação em que vivemos, porque tendemos a ignorar o outro e a solapar as subjetividades estrangeiras por meio de construções simbólico-discursivas investidas de simplismos, rótulos e preconceitos, engendrando incomunicação, incompreensão e relevando a dificuldade que temos de lidar e respeitar as diferenças e eliminar visões estereotipadas acerca do outro.

\section{CONSIDERAÇÕES FINAIS}

A presente proposta descritiva e exploratória buscou evidenciar a necessidade de uma comunicação intercultural apropriada por parte das organizações contemporâneas em tempos de redes sociais digitais. A estrutura comunicacional ágil, de fácil replicação e grande alcance das redes obriga as organizações contemporâneas a serem vigilantes com a postura de seus colaboradores e com sua própria conduta, sob pena de terem a reputação colocada em xeque, gerando prejuízos de ordem intangível e financeira.

Selecionamos dois casos que ilustram com propriedade a necessidade de uma gestão de relacionamento intercultural que seja capaz de negociar significados culturais. Nos casos em questão, da funcionária da IAC que emitiu comentário racista no Twitter, e da Adidas, que lançou camisetas que aludiam ao turismo sexual no Brasil, as empresas se mostraram aptas a responder rapidamente e de forma satisfatória, mas não planejaram estrategicamente, antecipando e dimensionando as diferenças culturais.

Os episódios também ilustram a capacidade de reverberação das redes sociais digitais, com assuntos que transcendem fronteiras geográficas e culturais. Os usuários (de diferentes culturas) agora são ativos no processo, já que produzem, selecionam, repercutem, garantem a perenidade das informações. As redes se transvestem em plataformas de mobilização, de alternativa à comunicação dominante, facilitam o engajamento e permitem forjar (ou reafirmar) identidades comprometidas - uma aposta na visibilidade efêmera e que exige a ressemantização da comunicação organizacional. 
Os casos aqui apresentados revelam que nossos cuidados ainda se restringem àquilo que nos é comum, coloca em xeque a suposta formação humanística da área de comunicação e traz à baila uma necessidade premente: a formação de corações grandes, o que nos convida a pensar em uma formação mais ligada ao saber-cuidar, a destrezas que não se encontram apenas nos livros, mas no olhar crítico para nosso eu, para quem somos em nós e quem somos no outro, para o respeito às complexas culturas em um universo investido de intolerância e ridicularização da gentileza e da empatia. De acordo com Wolton (2006), 0 choque de culturas é uma realidade da vida atual. Portanto, precisamos fazer de tudo para evitar que ele se transforme em um conflito de civilizações: eis a comunicação não como uma panaceia, mas como um alicerce fundamental para a manutenção da vida e a produção de novas sensibilidades.

\section{REFERÊNCIAS}

AGÊNCIA BRASIL. Adidas retira das lojas camisetas com apelo sexual. Revista Exame, 25 fev. 2014. Disponível em: <http:// exame.abril.com.br/marketing/noticias/adidas-retira-das-lojas-camisetas-com-apelo-sexual>. Acesso em: 23 jul. 2014.

CASTELLS, Manuel. Redes de indignação e esperança: movimentos sociais na era da internet. Rio de Janeiro, Zahar, 2013.

COUTINHO, Filipe. Adidas vai retirar do mercado camisetas do Brasil com apelo sexual. Folha de S.Paulo, 25 fev. 2014. Disponível em: <http://wwwl.folha.uol.com.br/esporte/folhanacopa/2014/02/1417599-adidas-diz-que-vai-retirar-do-mercado-camisetasdo-brasil-com-apelo-sexual.shtml>. Acesso em: 07 jul. 2014.

DINO, Flávio. Embratur repudia vínculo de imagem do Brasil à conotação sexual. Instituto Brasileiro de Turismo (Embratur), 25 fev. 2014. Disponível em: <http://www.embratur.gov.br/piembratur/opencms/salalmprensa/noticias/arquivos/Ebrtur_reudi_ vinculo_de_ige_do_Brsil_conotco_sexul.html>.Acesso em: 07 jul. 2014.

FERRARI, Maria Aparecida. Gestão da comunicação intercultural nas organizações brasileiras em tempos de globalização. In: SANTOS, Célia Maria Retz Godoy dos. Relações públicas. faces e interfaces. Bauru: FAAC, 2013. p. 87-102,

JORNAL DO BRASIL. IAC demite relações públicas que publicou mensagem racista nas redes sociais. 22 dez. 2013. Disponível em:<http://www.jb.com.br/internacional/noticias/2013/12/22/iac-demite-relacoes-publicas-que-publicou-mensagem-racistanas-redes-sociais/\#>. Acesso em: 06 jul. 2014.

LIPOVETSKY, Gilles. Metamorfoses da cultura: ética, mídia e empresa. Porto Alegre, Sulina, 2004.

NOGUEIRA, Kiko. "Indo para a África. Espero que não pegue aids": a saga de um post racista os nossos dias. Diário do Centro do Mundo, 21 dez. 2013. Disponível em: <http://www.diariodocentrodomundo.com.br/indo-para-a-africa-espero-que-nao-pegueaids-a-saga-de-um-post-racista-e-os-nossos-dias/>. Acesso em: 06 jul. 2014.

RAMONET Ignacio. A explosão do jornalismo na era digital. In: MORAES, Denis de; RAMONET, Ignacio; SERRANO, Pascual. Mídia, poder e contrapoder. da concentração monopólica à democratização da informação. São Paulo: Boitempo; Rio de Janeiro: Faperj, 2013. 
RECUERO, Raquel. Redes sociais na internet, difusão de informação e jornalismo: elementos para discussão. In: SOSTER, Demétrio de Azeredo; FIRMINO, Fernando (Org.). Metamorfoses jornalísticas 2: a reconfiguração da forma. Santa Cruz do Sul: Unisc, 2009.

Redes sociais na internet. Porto Alegre: Sulina, 2010.

RIBEIRO, Anely. Aspectos sobre relações públicas internacionais, cultura e linguagem. Curitiba: UFPR, 2003. Disponível em: <http://www.sinprorp.org.br/ clipping/2005/aspectos\%20sobre\%20relacoes\%20publicas.pdf>. Acesso em: 10 out. 2007.

RODRIGO ALSINA, Miguel. La comunicación intercultural. Portal Comunicación - Instituto de la Comunicación UAB. Lecciones del Portal. [1990]. Disponível em: <http://www.portalcomunicacion.com/esp/n_aab_lec_print.asp?id_seccio=7>. Acesso em: 26 out. 2007.

SANTOS, Milton. Por uma outra globalização. 23. ed. Rio de Janeiro: Record, 2013.

SUA FRANQUIA.COM. Apresentação da franquia Adidas. 2014. Disponível em: <http://www.suafranquia.com/franquias/ vestuario/roupas-e-acessorios/franquia-adidas/>. Acesso em: 16 jul. 2014.

WOLTON, Dominique. É preciso salvar a comunicação. São Paulo: Paulus. 2006. Informar não é comunicar. Porto Alegre: Sulina. 2011.

Artigo recebido em 30.07.2014 e aprovado em 06.10.2014. 